Polymer Journal, Vol. 38, No. 7, pp. 716-723 (2006)

(C) 2006 The Society of Polymer Science, Japan

\title{
Synthesis and Characterization of Main Chain Polyimides Containing Chalcone Derivatives for LC Alignment
}

\author{
Helena Tunell, ${ }^{1, \dagger}$ Muhammed Selo, ${ }^{1}$ Kent SKarp, ${ }^{1}$ and Jöns Hilborn ${ }^{2}$ \\ ${ }^{1}$ Dalarna University, SE-78170 Borlänge, Sweden \\ ${ }^{2}$ Department of Materials Chemistry, Uppsala University, SE-75121 Uppsala, Sweden
}

(Received January 20, 2006; Accepted March 15, 2006; Published June 9, 2006)

\begin{abstract}
Two soluble polyimides containing chalcone derivatives in the main chains were successfully prepared using the Mitsunobu reaction at room temperature, reacting diols with diimides. With this reaction procedure the high temperature imidization step normally needed for the synthesis of polyimides is avoided and the polymers can be used for temperature sensitive applications. The main chain polyimides were characterized with FT-IR, NMR and DSC and the extent of the photoreaction was measured with FT-IR and UV-vis spectroscopy. Isobestic points were observed in the absorption spectral changes at the early stage of UV irradiation as a result of a single photochemical process. Further photoirradiation is accompanied by deviation from the isobestic points, implying that another photochemical process has started. With FT-IR investigations it was concluded that photodimerization is the process occurring at low UV exposure doses and that trans-cis isomerization is starting simultaneously at higher doses. The optical anisotropic properties were investigated upon exposure of the polymers as thin films to linearly polarized UV (LPUV) light of different doses. Selected crosslinking in the parallel direction relative to the direction of the LPUV light and subsequent optical anisotropy in the film were achieved. [doi:10.1295/polymj.PJ2005218]

KEY WORDS Photoalignment / Chalcone / Polyimide / Photocrosslinking / Polymer Synthesis /
\end{abstract}

Thin polyimide films are commonly employed as alignment layers for liquid crystal displays (LCDs). Polyimides are thermally and chemically stable, have nice mechanical properties, are insoluble in and do not effect liquid crystals and polyimides provide high quality stable LC alignment with high anchoring energy. ${ }^{1}$ In the production of LCDs, the alignment of liquid crystals is normally achieved by coating the substrate with soluble poly(amic acid) which is imidized at high temperature to polyimide ${ }^{2}$ followed by rubbing with a cloth to enable alignment. However, this high temperature reaction obliviates the use of temperature sensitive substrates such as flexible polymer films. Other drawbacks of this technology are the generation of electric charges and the risk of contamination, being a contact method. An alternative technique to rubbing is photoalignment, i.e., exposing photosensitive polymers to linearly polarized UV (LPUV) light. ${ }^{3,4}$ Various methods of photoalignment have been reported based on photoinduced anisotropic $[2+2]$ dimerization, ${ }^{5}$ isomerization, ${ }^{6}$ and decomposition $^{7}$ reactions. Some types of photoactive polymers involve not only [2+2] dimerization but also transcis photoisomerization. ${ }^{8}$ Many different materials have been used for photoalignment, polyvinylcinnamates being one of the most common ones. ${ }^{9}$ A reason why these molecules align liquid crystals when exposed to LPUV light is that [2+2] cycloaddition causes anisotropic depletion of the photoactive group, ${ }^{5}$ another being that the trans-cis isomerization is responsible while dimerization enhances the thermal stability. ${ }^{10}$ Among many promising photosensitive groups, the chalcone group has been widely studied and affords high sensitivity to UV radiation. ${ }^{11,12} \mathrm{~A}$ polymer providing stable alignment with high photodimerization rate is expected by combining the nice properties of polyimide with the chalcone chromophore. Earlier investigations have mostly concerned polyimides bearing the chalcone moiety in the side chain. ${ }^{13,14}$ The thermal and optical stabilities are, however, not sufficiently high for these materials. ${ }^{15}$ When placing the photosensitive groups in the main chain the stability is expected to improve. ${ }^{17}$ Only a few investigations have been made concerning polyimides with chalcone chromophores in the main chain. ${ }^{16,17}$ These polyimides are synthesized in the common two-step procedure reacting dianhydride with diamine to provide poly(amic acid) precursor polymers, followed by a separate imidization process. In this work we found a new synthesis route to avoid the two-step procedure by using the Mitsunobu reaction ${ }^{18}$ at room temperature. The fully imidized polyimide is formed in one step and the poly(amic acid) intermediate is eliminated and thus curing at high temperature is avoided. The synthesized polymers are soluble in some common solvents for easy application to the substrate, but insoluble in the LC material. The synthesis of two soluble photoactive polyimides containing chalcone

${ }^{\dagger}$ To whom correspondence should be addressed (Tel: +46-23-778655, Fax: +46-23-778670, E-mail: htu@du.se). 
chromophores in the main chain are reported in this work, using Mitsunobu reaction conditions for the polycondensation of the monomers. The polyimides were characterized with FT-IR, NMR and DSC. The chemical photoreaction upon exposure to UV light was investigated with FT-IR and UV-vis spectroscopy both for solutions of the polyimides and for thin films. The optical anisotropic properties were investigated upon exposure of the polymers as thin films to LPUV light of different doses.

\section{EXPERIMENTAL}

\section{Materials}

The starting materials were obtained from SigmaAldrich. Anhydrous tetrahydrofuran (THF) and dimethylsulfoxide (DMSO) were obtained with high degree of purity. Triphenylphosphine was recrystallized from ethanol before use.

\section{Monomer Synthesis}

1-[4-(2-Hydroxy-ethoxy)-phenyl]-ethanone (II). Sodium hydroxide $(4.8 \mathrm{~g}, 0.12 \mathrm{~mol})$ was dissolved in 2butanone $(300 \mathrm{~mL}) .4$-Hydroxyacetophenone $(16.34 \mathrm{~g}$, $0.12 \mathrm{~mol}), \mathrm{NaI}(18.0 \mathrm{~g}, 0.12 \mathrm{~mol})$ and chloroethanol $(9.66 \mathrm{~g}, 0.12 \mathrm{~mol})$ were added. The mixture was vigorously stirred for 3 days at $60^{\circ} \mathrm{C}$. The solvent was evaporated. The crude product was washed with aqueous $\mathrm{NaOH}(300 \mathrm{~mL} 0.4 \mathrm{M})$ to remove the formed salt. The product was extracted with diethyl ether and dried with $\mathrm{MgSO}_{4}$. Yield: $32 \%$. mp: $74{ }^{\circ} \mathrm{C}$. IR $\left(\mathrm{cm}^{-1}\right): 3403$ $(\mathrm{OH}), 1650(\mathrm{C}=\mathrm{O}), 1595,1571,1512(\mathrm{Ar} \mathrm{C}=\mathrm{C})$. ${ }^{1} \mathrm{H}$ NMR $\left(\mathrm{CDCl}_{3}\right): \delta(\mathrm{ppm})=7.92(\mathrm{t}, 2 \mathrm{H}, \mathrm{Ar}-\mathrm{CH})$, 6.94 (t, 2H, Ar-CH), 4.14 (t, 2H, $\left.\mathrm{CH}_{2}\right), 3.99$ (d, $2 \mathrm{H}$, $\left.\mathrm{CH}_{2}\right), 2.55\left(\mathrm{~s}, 3 \mathrm{H}, \mathrm{CH}_{3}\right), 2.03(\mathrm{~s}, 1 \mathrm{H}, \mathrm{OH})$.

4-(2-Hydroxy-ethoxy)-benzaldehyde (IV). Sodium hydroxide $(4.8 \mathrm{~g}, 0.12 \mathrm{~mol})$ was dissolved in 2-butanone $(300 \mathrm{~mL})$. 4-hydroxybenzaldehyde $(14.65 \mathrm{~g}, 0.12$ $\mathrm{mol}), 18.0 \mathrm{~g}(0.12 \mathrm{~mol}) \mathrm{NaI}$ and $9.66 \mathrm{~g}(8.05 \mathrm{~mL})(0.12$ $\mathrm{mol})$ chloroethanol were added. The mixture was vigorously stirred at $60^{\circ} \mathrm{C}$ for $2 \mathrm{~d}$. After removal of the solvent the crude product was washed with aqueous $\mathrm{NaOH}(300 \mathrm{~mL} 0.4 \mathrm{M})$ to remove the formed salt. The product was extracted with diethyl ether and dried with $\mathrm{MgSO}_{4}$. Yield: $75 \%$. IR $\left(\mathrm{cm}^{-1}\right)$ : $3402(\mathrm{OH})$, 1677 (aldehyde $\mathrm{C}=\mathrm{O}), 1595,1575,1509(\mathrm{Ar} \mathrm{C}=\mathrm{C})$. ${ }^{1} \mathrm{H}$ NMR $\left(\mathrm{CDCl}_{3}\right): \delta(\mathrm{ppm})=7.42(\mathrm{t}, 2 \mathrm{H}, \mathrm{Ar}-\mathrm{CH})$, $6.86(\mathrm{t}, 2 \mathrm{H}, \mathrm{Ar}-\mathrm{CH}), 6.55(\mathrm{~s}, 1 \mathrm{H}, \mathrm{CH}=\mathrm{O}), 4.11(\mathrm{~d}$, $\left.2 \mathrm{H}, \mathrm{CH}_{2}\right), 4.06\left(\mathrm{~s}, 2 \mathrm{H}, \mathrm{CH}_{2}\right), 2.85(\mathrm{~s}, 1 \mathrm{H}, \mathrm{OH})$.

1,3-Bis-[4-(2-hydroxy-ethoxy)-phenyl]-propenone (V). IV (3.32 g, $20 \mathrm{mmol})$ was mixed with $10 \mathrm{~mL}$ methanol using magnetic stirring at room temperature. II $(3.60 \mathrm{~g}, 20 \mathrm{mmol})$ was dissolved in $20 \mathrm{~mL}$ methanol and added to the reaction flask. Finally a 3\% methanolic $\mathrm{NaOH}$ solution $(20 \mathrm{~mL})$ was added dropwise.
The mixture was left for $2 \mathrm{~d}$ with stirring and another $2 \mathrm{~d}$ without stirring. The solution was diluted with water and neutralized by dropwise addition of 50\% $\mathrm{HCl}$. The precipitate was filtered off and recrystallized from ethanol. Yield: $52 \%$. mp: $148.5^{\circ} \mathrm{C}$. IR $\left(\mathrm{cm}^{-1}\right)$ : $3384(\mathrm{OH}), 1653(\mathrm{C}=\mathrm{O}), 1601$ (chalcone $\mathrm{C}=\mathrm{C}$ str, Ar $\mathrm{C}=\mathrm{C}$ ), 1569, 1507 (Ar $\mathrm{C}=\mathrm{C}), 983$ (chalcone $\mathrm{C}-$ $\mathrm{H}$ out of plane def). ${ }^{1} \mathrm{H}$ NMR (DMSO- $\left.d_{6}\right): \delta(\mathrm{ppm})=$ $8.15(\mathrm{~d}, 2 \mathrm{H}, \mathrm{Ar}-\mathrm{CH}), 7.84(\mathrm{~d}, 2 \mathrm{H}, \mathrm{Ar}-\mathrm{CH}), 7.82(\mathrm{~d}$, $2 \mathrm{H}, \mathrm{C}=\mathrm{OCH}=\mathrm{CH}), 7.68 \quad(\mathrm{~d}, 2 \mathrm{H}, \mathrm{C}=\mathrm{OCH}=\mathrm{CH})$, $7.08(\mathrm{~d}, 2 \mathrm{H}, \mathrm{Ar}-\mathrm{CH}), 7.02(\mathrm{~d}, 2 \mathrm{H}, \mathrm{Ar}-\mathrm{CH}), 4.95$ (t, $1 \mathrm{H}, \mathrm{OH}), 4.93(\mathrm{t}, 1 \mathrm{H}, \mathrm{OH}), 4.11\left(\mathrm{t}, 2 \mathrm{H}, \mathrm{CH}_{2}\right), 4.06$ (t, $2 \mathrm{H}, \mathrm{CH}_{2}$ ), $3.76\left(\mathrm{t}, 2 \mathrm{H}, \mathrm{CH}_{2}\right), 3.73\left(\mathrm{t}, 2 \mathrm{H}, \mathrm{CH}_{2}\right)$.

Pyrrolo[3,4-f]isoindole-1,3,5,7-tetraone (Pyromellitic Diimide) (VII). Pyromellitic dianhydride $(10.10 \mathrm{~g}, 46.3 \mathrm{mmol})$ and urea $(4.24 \mathrm{~g}, 70.6 \mathrm{mmol})$ were mixed in a reaction flask. The temperature was raised to $200{ }^{\circ} \mathrm{C}$ for $2 \mathrm{~h}$. After cooling to room temperature the resulting solid was ground into a fine powder and the reaction was continued at $200^{\circ} \mathrm{C}$ for another hour. The crude product was washed with distilled water several times to remove unreacted urea. The product was dried and recrystallized from ethanol. Yield: $83 \%$. mp: $453^{\circ} \mathrm{C}$. IR $\left(\mathrm{cm}^{-1}\right): 3200(\mathrm{NH}), 1772$ (imide $\mathrm{C}=\mathrm{O}$ asym str), 1692 (imide $\mathrm{C}=\mathrm{C}$ sym str). ${ }^{1} \mathrm{H}$ NMR $\left(\mathrm{DMSO}-d_{6}\right): \delta(\mathrm{ppm})=8.1(\mathrm{~s}, 2 \mathrm{H}, \mathrm{Ar}-\mathrm{CH})$, $11.85(\mathrm{~s}, 2 \mathrm{H}, \mathrm{NH})$.

4,4'-(Hexafluoroisopropylidene)diphthalimide $(\boldsymbol{X})$. 4,4'(Hexafluoroisopropylidene) diphthalic anhydride $(4.98 \mathrm{~g}, 11.2 \mathrm{mmol})$ and urea $(1.03 \mathrm{~g}, 17.2 \mathrm{mmol})$ were mixed in a reaction flask. The temperature was raised to $200^{\circ} \mathrm{C}$ for $2 \mathrm{~h}$. After cooling to room temperature the resulting solid was ground into a fine powder and the reaction was continued at $200^{\circ} \mathrm{C}$ for another hour. The crude product was washed with distilled water several times to remove unreacted urea. The product was dried and recrystallized from ethanol. Yield: $83 \%$. mp: $320^{\circ} \mathrm{C}$. IR $\left(\mathrm{cm}^{-1}\right): 3300(\mathrm{NH})$, 1782 (imide $\mathrm{C}=\mathrm{O}$ asym str), 1713 (imide $\mathrm{C}=\mathrm{C}$ sym str). ${ }^{1} \mathrm{H}$ NMR $\left(\right.$ DMSO- $\left.d_{6}\right): \delta(\mathrm{ppm})=7.64(\mathrm{~s}, 2 \mathrm{H}$, $\mathrm{Ar}-\mathrm{CH}), 7.82(\mathrm{~d}, 2 \mathrm{H}, \mathrm{Ar}-\mathrm{CH}), 7.99$ (d, 2H, Ar-CH), $11.70(\mathrm{~s}, 2 \mathrm{H}, \mathrm{NH})$.

\section{Polymer Synthesis}

PIC-1 (VIII). Triphenylphosphine (4.88 g, 18.6 mmol) was mixed with anhydrous DMSO $(15 \mathrm{~mL})$ in a $100 \mathrm{~mL}$ schlenk flask. The reaction mixture was stirred and purged with nitrogen gas. VII $(1.34013 \mathrm{~g}$, $6.2 \mathrm{mmol})$ and $\mathbf{V}(2.03589 \mathrm{~g}, 6.2 \mathrm{mmol})$ were added. After dropwise addition of diisopropyl azodicarboxylate, DIAD $(3.76 \mathrm{~g}, 18.6 \mathrm{mmol})$ in $2.5 \mathrm{~mL}$ anhydrous DMSO the reaction mixture was left to stir for $4 \mathrm{~d}$ at room temperature. The polymer was precipitated in $500 \mathrm{~mL}$ cold methanol, filtered off and dried in vacuum oven. Soxhlet extraction in methanol for $3 \mathrm{~d}$ was 
made to purify the polymer. Yield: $94 \% .{ }^{1} \mathrm{H}$ NMR $\left(\mathrm{DMSO}-d_{6}\right) \delta(\mathrm{ppm}): 8.0-8.3(\mathrm{~m}, 4 \mathrm{H}, \mathrm{Ar}-\mathrm{CH}), 7.5-$ $7.9(\mathrm{~m}, 4 \mathrm{H}, \mathrm{Ar}-\mathrm{CH}, \mathrm{CH}=\mathrm{CH}), 6.9-7.1(\mathrm{~m}, 4 \mathrm{H}, \mathrm{Ar}-$ $\mathrm{CH}), 4.0-4.4\left(\mathrm{~m}, 8 \mathrm{H}, \mathrm{CH}_{2}-\mathrm{O}, \mathrm{CH}_{2}-\mathrm{N}\right) .{ }^{13} \mathrm{C}$ NMR $\left(\mathrm{DMSO}-\mathrm{d}_{6}\right) \delta(\mathrm{ppm}): 189$ (chalcone $\mathrm{C}=\mathrm{O}$ ), 167 (imide $\mathrm{C}=\mathrm{O}), 162$ (Ar C-O), 159 (Ar C-O), $143(\mathrm{CH}=\mathrm{CH}$, carbon away from carbonyl), 137 (Ar C connected to chalcone carbonyl end), 131 (4C Ar), 130 (2C Ar), 128 (4C Ar), 127 (Ar C connected to chalcone), 121 $(\mathrm{CH}=\mathrm{CH}$, carbon close to carbonyl), 114 (4C Ar), 65 $\left(\mathrm{O}-\mathrm{CH}_{2}\right), 37\left(\mathrm{~N}-\mathrm{CH}_{2}\right) . \mathrm{IR}\left(\mathrm{cm}^{-1}\right)$ : 1775 (imide $\mathrm{C}=\mathrm{O}$ asym str), 1727 (imide $\mathrm{C}=\mathrm{O}$ sym str), 1658 (chalcone $\mathrm{C}=\mathrm{O}$ str), 1601 (chalcone $\mathrm{C}=\mathrm{C}$ str, $\mathrm{Ar} \mathrm{C}=\mathrm{C}$ ), 1572, 1509 ( $\mathrm{Ar} \mathrm{C}=\mathrm{C}$ ), 987 (chalcone $\mathrm{C}-\mathrm{H}$ out of plane def). The glass transition temperature was $160^{\circ}$ C. $M_{\mathrm{n}}=$ 6,500 g/mol, NMR.

PIC-2 (XI). Triphenylphosphine $(3.70 \mathrm{~g}, 14.1$ mmol) was dissolved in anhydrous THF $(14 \mathrm{~mL})$ in a $100 \mathrm{~mL}$ schlenk flask. The reaction mixture was stirred and purged with nitrogen gas. X $(2.07285 \mathrm{~g}$, $4.7 \mathrm{mmol})$ and $\mathbf{V}(1.54339 \mathrm{~g}, 4.7 \mathrm{mmol})$ were added. After dropwise addition of diisopropyl azodicarboxylate, DIAD $(2.85 \mathrm{~g}, 14.1 \mathrm{mmol})$ in $4 \mathrm{~mL}$ anhydrous THF the solution was left to stir for $4 \mathrm{~d}$ at room temperature. The polymer was precipitated in $500 \mathrm{~mL}$ cold methanol. To purify the polymer Soxhlet extraction in methanol for $3 \mathrm{~d}$ was made. Yield $=98 \%$. ${ }^{1} \mathrm{H}$ NMR $\left(\mathrm{DMSO}-d_{6}\right): \delta(\mathrm{ppm})=8.1-7.6(\mathrm{~m}, 16 \mathrm{H}$, $\mathrm{Ar}-\mathrm{CH}, \mathrm{CH}=\mathrm{CH}), 4.0-4.4\left(\mathrm{~m}, 8 \mathrm{H}, \mathrm{CH}_{2}-\mathrm{O}, \mathrm{CH}_{2}-\mathrm{N}\right)$. ${ }^{13} \mathrm{C}$ NMR (DMSO- $\left.d_{6}\right) \delta(\mathrm{ppm}): 189$ (chalcone $\mathrm{C}=\mathrm{O}$ ), 168 (imide $\mathrm{C}=\mathrm{O}$ ), 163 (Ar C-O), 159 (Ar C-O), 147 (2C Ar close to $\left.\mathrm{CF}_{3}\right), 143(\mathrm{CH}=\mathrm{CH}$, carbon away from carbonyl), 137 (Ar C connected to chalcone carbonyl end), 131 (4C Ar), 130 (2C Ar), 128 (8C Ar), 127 (Ar $\mathrm{C}$ connected to chalcone), $122\left(\mathrm{CF}_{3}\right), 121$ $(\mathrm{CH}=\mathrm{CH}$, carbon close to carbonyl), $114(4 \mathrm{C} \mathrm{Ar})$, $65\left(\mathrm{O}-\mathrm{CH}_{2}\right), 38\left(\mathrm{C}-\left(\mathrm{CF}_{3}\right)_{2}\right), 37\left(\mathrm{~N}-\mathrm{CH}_{2}\right)$. IR $\left(\mathrm{cm}^{-1}\right)$ : 1779 (imide $\mathrm{C}=\mathrm{O}$ asym str), 1722 (imide $\mathrm{C}=\mathrm{O}$ sym str), 1658 (chalcone $\mathrm{C}=\mathrm{O}$ str), 1601 (chalcone $\mathrm{C}=\mathrm{C}$ str, $\mathrm{Ar} \mathrm{C}=\mathrm{C}$ ), 1573, 1509 ( $\mathrm{Ar} \mathrm{C}=\mathrm{C}$ ), 982 (chalcone $\mathrm{C}-\mathrm{H}$ out of plane def). The glass transition temperature was $125^{\circ}$ C. $M_{\mathrm{n}}=7,400 \mathrm{~g} / \mathrm{mol}$, NMR.

\section{Characterization}

Infrared spectra were measured on a Perkin Elmer One fourier transform spectrometer. ${ }^{1} \mathrm{H}$ NMR spectra were obtained with a JEOL $400 \mathrm{MHz}$ spectrometer with the solvent proton signal as an internal standard. Thermal analysis was performed on a Perkin Elmer DSC Pyris Diamond at a heating rate of $10^{\circ} \mathrm{C} \mathrm{min}^{-1}$. The second heating scan was used to determine the glass transition temperature $\left(T_{\mathrm{g}}\right)$. UV-vis spectra were recorded using a Perkin Elmer Lambda 900 photospectrometer. For the measurements in solution, the polymers were dissolved in $\mathrm{CH}_{2} \mathrm{Cl}_{2}$ and illuminated with a $365 \mathrm{~nm}$ UV lamp. The concentrations of PIC1 and PIC-2 were $0.02 \mathrm{~g} / \mathrm{L}$ and $0.10 \mathrm{~g} / \mathrm{L}$ respectively. Thin films of the polymers were prepared by spincoating (1500 rpm for $6 \mathrm{~s}$ and $3000 \mathrm{rpm}$ for $60 \mathrm{~s}$ ) a $2 \%$ cyclopentanone solution of the polymers onto quartz substrates. After evaporation of solvent in vacuum oven at $60^{\circ} \mathrm{C}$ for $24 \mathrm{~h}$ they were exposed to LPUV light using an Ushio photoalignment lamp in nitrogen atmosphere. The thickness of the films were measured to $60 \mathrm{~nm}$ using a Veeco Dektak ${ }^{3}$ ST surface profile measuring system.

\section{RESULTS AND DISCUSSION}

\section{Monomer Synthesis}

The synthetic procedures are illustrated in Figure 1 and Figure 2.

Monomer $\mathbf{V}$ was prepared in 3 steps. First 4-hydroxyacetophenone was reacted with chloroethanol in the presence of sodium hydroxide and sodium iodide to give 1-[4-(2-hydroxy-ethoxy)-phenyl]-ethanone (II). ${ }^{19}$ The spacer was added in the same way to 4-hydroxybenzaldehyde to give 4-(2-hydroxy-ethoxy)-benzaldehyde (IV). The chalcone with spacers on both sides was prepared by reacting II and IV in a methanolic solution of sodium hydroxide at room temperature. ${ }^{20}$ Monomer VII was prepared in a single step. Pyromellitic dianhydride was reacted with urea at $200^{\circ} \mathrm{C}$ for a total of $3 \mathrm{~h} .{ }^{21}$ Monomer $\mathbf{X}$ was prepared similar to monomer VII.

\section{Polymer Synthesis}

The two polymers, PIC-1 and PIC-2, were successfully synthesized by polycondensation under Mitsunobu conditions ${ }^{18}$ of two monomers on the basis of $\mathrm{N}$ alkylation of the diimide. Both monomers were reacted under nitrogen with triphenylphosphine and diisopropyl azodicarboxylate, DIAD in anhydrous solvents. ${ }^{21}$ The polymerisation proceeds via an alcohol conversion to alkoxyphosphonium salt, which is a powerful alkyl donor group while the diimide anion acts as an alkyl group acceptor.

Polymer PIC-2 is more flexible than PIC-1 due to the hexafluoroisopropylidene linkage in between the stiff aromatic cores. This can be seen as a lower glass transition temperature for PIC-2, $125^{\circ} \mathrm{C}$, than for PIC$1,160^{\circ} \mathrm{C}$. The fluorogroups in PIC-2 also contributes to increased transparency ${ }^{22}$ compared to PIC-1.

The molecular weight of both compounds was rather low using this method. This problem has been reported earlier ${ }^{21,23}$ and could in this case be due to the rigid nature of the diimides retarding the Mitsunobu reaction. 


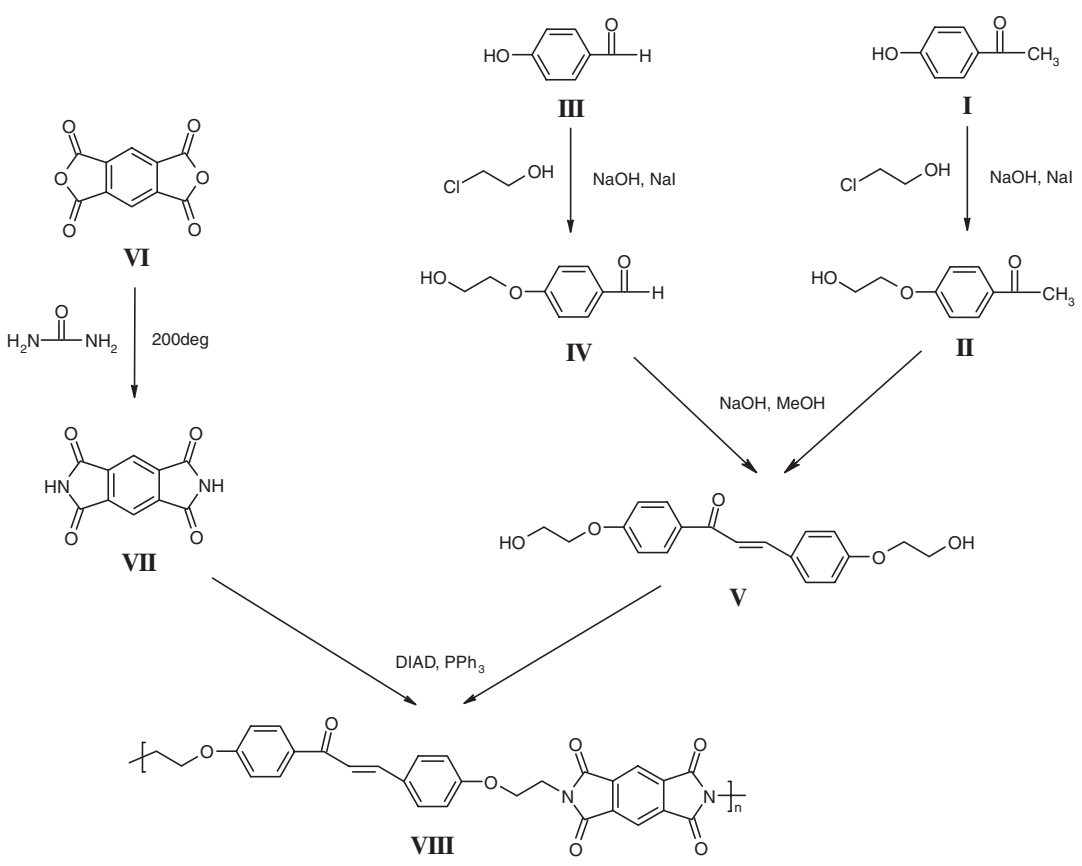

Figure 1. Synthetic procedure for PIC-1.

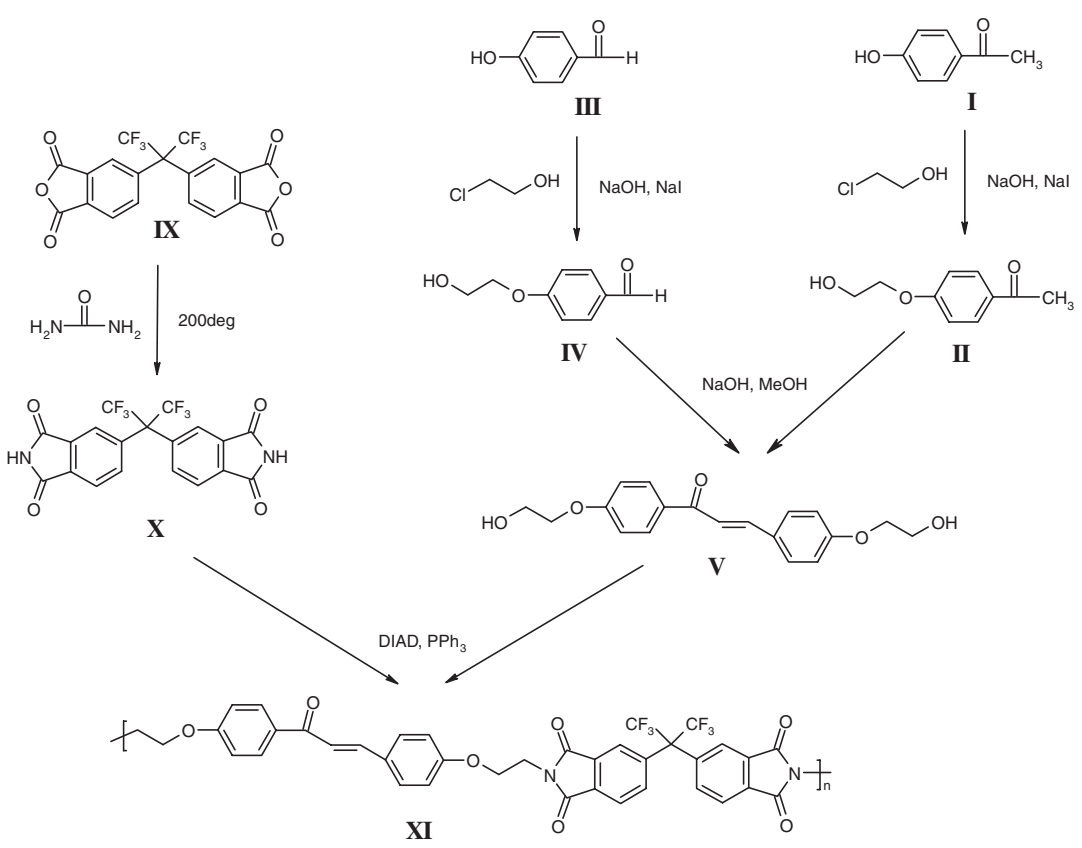

Figure 2. Synthetic procedure for PIC-2.

Photochemical Properties of PIC-1 and PIC-2

$\mathrm{UV}$-vis spectra of the two polymers were recorded in $\mathrm{CH}_{2} \mathrm{Cl}_{2}$ solution before and after different periods of exposure to UV light. Both trans-cis isomerization and dimerization of chalcone are expected upon exposure of the polymers to UV irradiation as illustrated in Figure 3.

The unimolecular isomerization occurs through a rotation mechanism from the trans- to the cis-form when the UV light has excited the $\pi$-electrons of the carbon-carbon double bond. The dimerization, which is a bimolecular reaction, results in a crosslinking of the polymer with formation of cyclobutane rings through a [2+2] cycloaddition of the carbon-carbon double bond. For the polymers in solution the chalcone moiety shows an absorption maximum at $336 \mathrm{~nm}$ for both PIC-1 (Figure 4) and PIC-2 (Figure 5) which is attributed to the $\pi-\pi^{*}$ transitions through the chalcone system for the trans-isomer.

The intensity of this absorption decreases fast upon exposure to UV light which indicates the disturbance of conjugation, either due to dimerization or trans-cis 


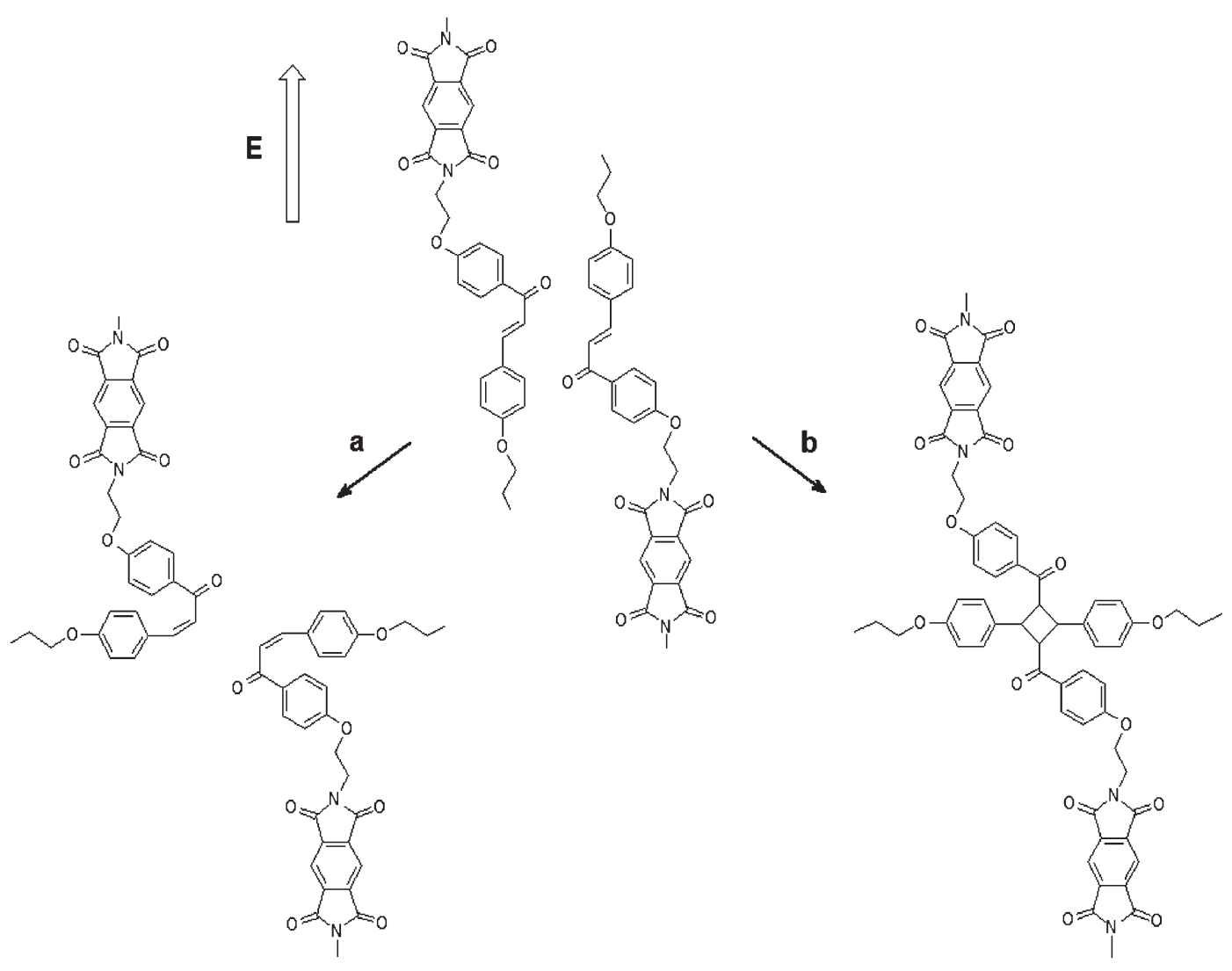

Figure 3. Photochemical reactions of PIC-1 upon exposure to UV light: (a) trans-cis isomerization and (b) [2+2] cycloaddition.

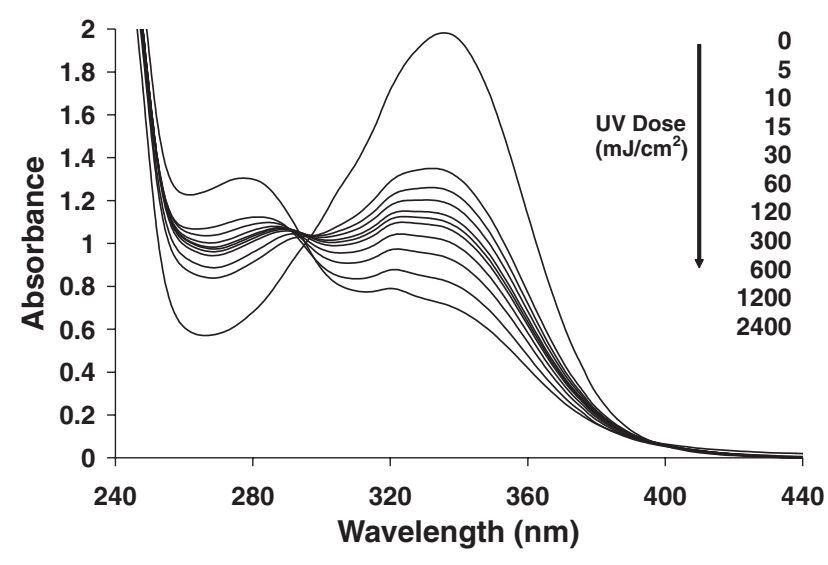

Figure 4. Absorption spectral changes of polymer PIC-1 in solution irradiated with unpolarized UV light.

isomerization. Simultaneously an increase of absorption is observed at $280 \mathrm{~nm}$ attributed to the photochemical product. For exposure doses less than $300 \mathrm{~mJ} / \mathrm{cm}^{2}$, there is an isosbestic point at $296 \mathrm{~nm}$ for both polymers which indicates an equilibrium between two species demonstrating that only one process occurs exclusively and only one photochemical product is formed. Further photoirradiation results in deviations from the isosbestic points which reveal the formation of more than one product and the speed of conversion gradually slows down. The peaks of both photochemical products, the cis-isomer and the

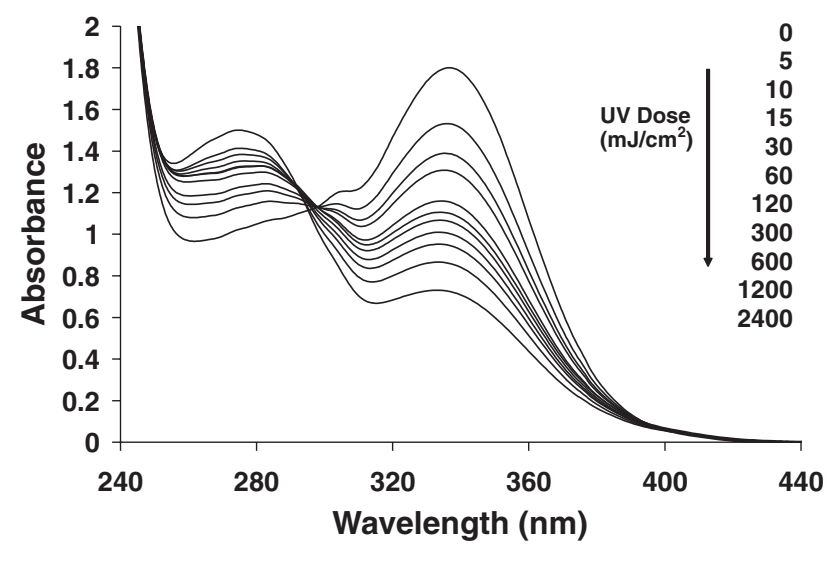

Figure 5. Absorption spectral changes of polymer PIC-2 in solution irradiated with unpolarized UV light.

dimer, are overlapping each other. After relaxation for a few hours there are no changes in the spectra which indicate that the products are stable. Thin films of the polymers were prepared by spincoating cyclopentanone solutions of the polymers onto quartz substrates. The absorption spectral changes of the two polymers PIC-1 (Figure 6) and PIC-2 (Figure 7) were studied upon exposure to linearly polarized UV light of different doses. $\mathrm{A}_{\|}$and $\mathrm{A}_{\perp}$ denote absorbances parallel and perpendicular to the electric vector of the LPUV light.

The unexposed film shows an absorption spectra 


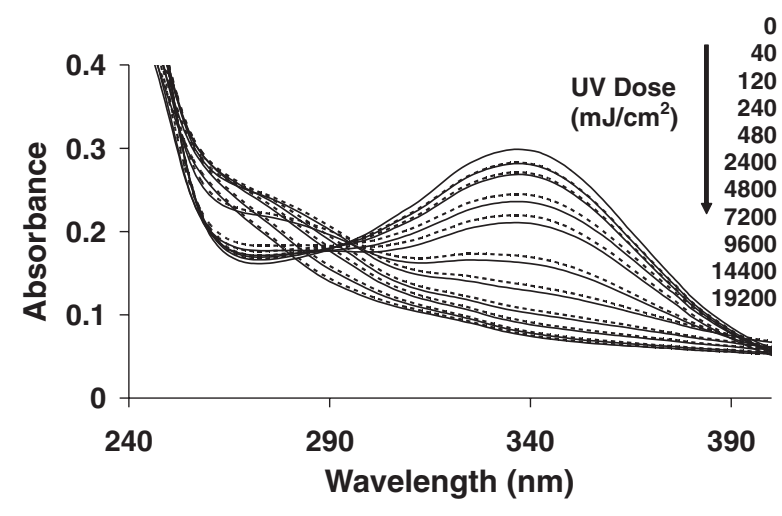

Figure 6. Absorption spectral changes of polymer PIC-1 as film irradiated with LPUV light.

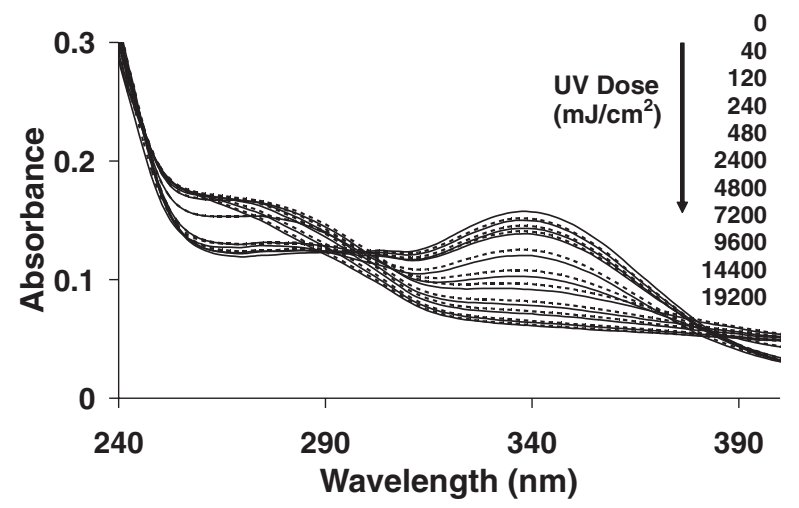

Figure 7. Absorption spectral changes of polymer PIC-2 as film irradiated with LPUV light.

profile similar to that in solution and with increasing exposure time there is a decrease of absorption at $336 \mathrm{~nm}$ (trans-isomer). For exposure doses up to $480 \mathrm{~mJ} / \mathrm{cm}^{2}$ an isobestic point is seen. After exposures of $7200 \mathrm{~mJ} / \mathrm{cm}^{2}$ both UV absorption peaks related to the trans-isomer and to the photochemical product, are decreasing and a decomposition of the polymer seem to be starting.

The perpendicular absorption at $336 \mathrm{~nm}$ was observed to be higher than the parallel absorption in the whole range of the irradiation time period. In Figure 8 , the difference spectra of the absorbances perpendicular and parallel to the electric field of the LPUV light are shown. For PIC-1 the maximum was obtained after exposure of $480 \mathrm{~mJ} / \mathrm{cm}^{2}$, while for PIC-2 the maximum was reached after a longer exposure of $2400 \mathrm{~mJ} / \mathrm{cm}^{2}$. When crosslinking occurs it exerts an effect on the remaining part of the chains in different amounts. For polymer PIC-1 which is the more rigid of the two, crosslinking effects the chains more, while it takes longer time for the more flexible PIC-2 until the network has achieved such order that it appears as a difference in anisotropy. The following decrease in anisotropy for longer periods

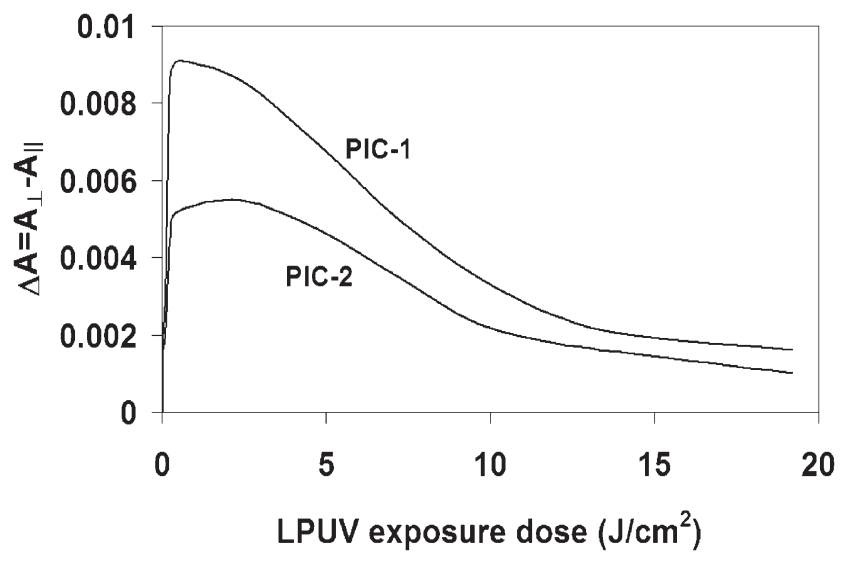

Figure 8. UV absorption difference spectra of the two polymer films PIC-1 and PIC-2 irradiated with UV light.

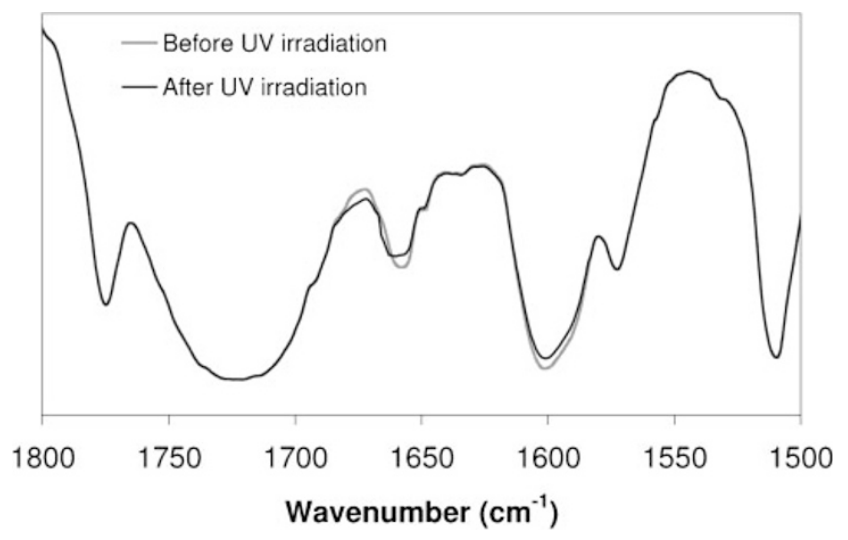

Figure 9. Infrared spectra of PIC-1 before and after UV irradiation.

of UV exposure is explained by a higher extent of crosslinking in any direction from the polarization direction of the UV light.

\section{Comparison of $U V$-vis and Infrared Spectroscopic Study}

UV-vis absorption spectral changes show any conversion of the trans-isomer with the dimer and the cisisomer as possible products. To be able to distinguish between the two products FT-IR measurements were made before and after different UV light exposure doses, see Figure 9.

Studies of the absorption at $1601 \mathrm{~cm}^{-1}$ which is related to the stretching vibrations of the olefinic carbon-carbon double bond in the chalcone moieties, show gradual decrease of the intensity with increasing UV light dose. The reason for the reduction of these absorptions is that the conjugated system of the chalcone is disrupted due to breaking of the double bond. In addition the intensity of the $\mathrm{C}=\mathrm{O}$ unsaturated ketone carbonyl stretching band at $1658 \mathrm{~cm}^{-1}$ is shifted and broadened with UV exposure time and a new absorption band, attributed to a saturated ketone car- 
bonyl stretching vibration, at $1672 \mathrm{~cm}^{-1}$ appears in the spectra of the two polymers after UV irradiation. The problem with the absorption spectral band at $1601 \mathrm{~cm}^{-1}$ is that it is normally superposed with the absorption bands of the double bonds in the benzene ring, but the benzene ring is not effected by UV light and the other two absorptions of the double bonds in the ring are not changed, thus any change in the absorption at $1601 \mathrm{~cm}^{-1}$ is due to a breaking of the double bond in chalcone. ${ }^{13,16,24}$ By monitoring the behaviour of the $1601 \mathrm{~cm}^{-1}$ absorption the extent of photocrosslinking can be investigated but trans-cis isomerization can not be followed.

The conversion of the trans-isomer was determined by the rate of disappearance of the carbon-carbon double bond using the following expression:

$$
\text { Conversion }(\%)=\left(\mathrm{A}_{0}-\mathrm{A}_{\mathrm{t}}\right) / \mathrm{A}_{0} \times 100
$$

where $A_{0}$ is the absorption intensity before irradiation and $A_{t}$ is the absorption intensity after different irradiation times. The result is presented in Figure 10 for PIC-1. The results for PIC-2 are similar.

Comparing the conversion of trans-isomer in the UV-vis spectra for solution and film it is obvious that the initial rate of conversion is much higher in solution than in film because the polymer chains have higher mobility in solution and the polymer in solution also reaches a higher total conversion than the film at the highest exposure dose. When the films are exposed to higher intensities than shown in Figure 10 the conversion seem to increase further, but in this case, as is seen in Figure 6, there is no continuing increase of product but instead a decomposition of the material is beginning. When comparing the IR curve and the UV-vis curve for the film in Figure 10 it is seen that initially the IR curve follows the UVvis curve. This confirms that at low exposures, as long as the isosbestic point is seen in the UV-vis spectra, a single photochemical process is taking place. This process is photocrosslinking since the results from

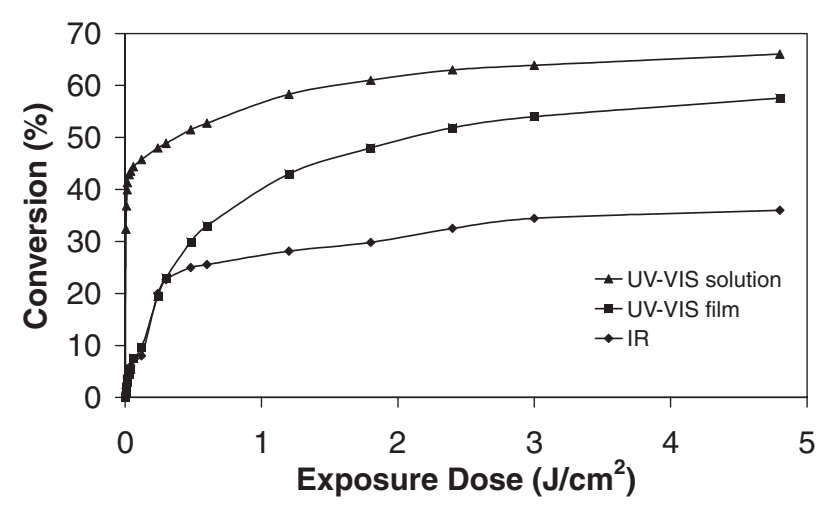

Figure 10. Conversion of PIC-1 as a function of exposure dose from UV-vis and IR spectroscopy.
FT-IR represent only the change in the concentration of carbon-carbon double bond due to breaking of the double bond. At larger UV exposure doses than $300 \mathrm{~mJ} / \mathrm{cm}^{2}$ the rate of conversion of the double bond is drastically decreased for the IR curve and it deviates from the UV-vis curve. This is in good agreement with the energy where the isobestic point is no longer seen in the UV vis absorption spectra. The deviation of the two curves happens because the competing trans-cis isomerization is starting and two products are formed simultaneously. With further photoirradiation the energy is enough for the rotation mechanism to take place and convert the trans-isomer to the cisform. This process can be followed with the UV-vis absorptions but not with the FT-IR absorptions. The isomerization and dimerization takes place simultaneously above $300 \mathrm{~mJ} / \mathrm{cm}^{2}$, but the crosslinking to a much smaller extent. Combining the results of the UV-vis and FT-IR measurements we find that for UV exposure doses of less than $300 \mathrm{~mJ} / \mathrm{cm}^{2}$ the polymers undergo photodimerization. At larger UV doses trans-cis isomerization is occurring as well but the degree of crosslinking is slowing down.

\section{REFERENCES}

1. "Polyimides Fundamentals and Applications," M. K. Ghosh and K. L. Mittal, Ed., Marcel Dekker Inc, New York, 1996.

2. K. Sakamoto, K. Usami, M. Kikegawa, and S. Ushioda, J. Appl. Phys., 93, 1039 (2003).

3. K. Ichimura, Chem. Rev., 100, 1847 (2000).

4. M. O’Neill and S. M. Kelly, J. Phys. D: Appl. Phys., 33, R67 (2000).

5. M. Schadt, K. Schmitt, V. Kozinkov, and V. Chigrinov, Jpn. J. Appl. Phys., 31, 2155 (1992).

6. Y. Kawanishi, T. Tamaki, T. Seki, M. Sakuragi, and K. Ichimura, Mol. Cryst. Liq. Cryst., 218, 153 (1992).

7. M. Hasegawa and Y. Taira, J. Photopolym. Sci. Technol., 8, 241 (1995).

8. S. Yamaki, M. Nakagawa, S. Morino, and K. Ichimura, Macromol. Chem. Phys., 202, 325 (2001).

9. M. Schadt, H. Seiberle, A. Schuster, and S. M. Kelly, Jpn. J. Appl. Phys., 34, L764 (1995).

10. K. Ichimura, Y. Akita, H. Akiyama, K. Kudo, and Y. Hayashi, Macromolecules, 30, 903 (1997).

11. D. N. Dhar, "The Chemistry of Chalcones and Related Compounds,” John Wiley \& Sons, Inc, New York, 1981.

12. Y. Makita, T. Natsui, S. Kimura, S. Nakata, M. Kimura, Y. Matsuki, and Y. Takeuchi, J. Photopolym. Sci. Technol., 11, 187 (1998).

13. D.-H. Choi and Y.-K. Cha, Bull. Korean Chem. Soc., 23, 469 (2002).

14. D.-M. Song, D.-M. Shin, S.-O. Choi, K.-Y. Choi, and Mi-Hieyi, Mol. Cryst. Liq. Cryst., 371, 269 (2001).

15. B. Park, Y. Jung, H.-H. Choi, H.-K. Hwang, Y. Kim, S. Lee, S.-H. Jang, M. Kakimoto, and H. Takezoe, Jpn. J. Appl. Phys., 37, 5663 (1998). 
16. K. Feng, M. Tsushima, T. Matsumoto, and T. Kurosaki, J. Polym. Sci., Part A: Polym. Chem., 36, 685 (1998).

17. T. Mihara, Y. Nakao, and N. Koide, Polym. J., 37, 162 (2005).

18. O. Mitsunobu, Synthesis, 1, 1 (1981).

19. D. J. Broer, J. Boven, and G. N. Mol, Makromol. Chem., 190, 2255 (1989).

20. M. Liu, P. Wilairat, and M.-L. Go, J. Med. Chem., 44, 4443
(2001).

21. T.-D. Kim, K.-S. Lee, G. U. Lee, and O.-K. Kim, Polymer, 41, 5237 (2000).

22. T. Omote, T. Yamaoka, and K. Koseki, J. Appl. Polym. Sci., 38, 389 (1989).

23. C. B. Yoon and H. K. Shim, J. Mater. Chem., 9, 2339 (1999).

24. A. Rehab and N. Salahuddin, Polymer, 40, 2197 (1999). 